\title{
PREFACE: FULLERENES AND NANOSTRUCTURES IN CONDENSED MATTER
}

The Jubilee X International Scientific Conference "Fullerenes and Nanostructures in Condensed Matter - FNSCM-2018," dedicated to the 90th anniversary of the National Academy of Sciences of Belarus, was successfully held in Minsk, Republic of Belarus, on August 20-23, 2018.

The aim of the conference was to exchange new ideas, scientific and technical information, to identify the promising ways of creating and developing new equipment and technologies, and to consider the problems of training scientists in the field of nanomaterials and nanotechnologies.

Among those who took part in the conference were 3 academicians, 2 corresponding members, 29 doctors of sciences, 32 candidates of sciences, 31 from among young scientists, 5 post-graduate students and 6 undergraduate ones. The reports presented at the conference covered a wide range of topics:

1. Fullerenes, carbon nanotubes, nanostructures, small particles and clusters, chemically modified nanoparticles and their properties.

2. Physicochemical principles and methods of producing fullerenes, various kinds of nanostructures and materials based on them.

3. Physical, physicochemical, and biochemical properties of materials containing nanostructures.

4. Use of nanostructures and nanomaterials.

5. Additive technologies.

6. Problems of nanotechnological education.

The Jubilee X International Scientific Conference was attended by representatives of research institutes, universities, industrial enterprises, as well as business communities and associations. At the conference, 138 scientists from Belarus, Russia, Ukraine, Azerbaijan, Moldova, Uzbekistan, Canada, and Iran presented their reports. Moreover, there were reports prepared jointly with scientists from Vietnam, Mongolia, and Poland which covered urgent interesting topics and initiated thorough discussions.

The program of the conference included "round-table" discussions at which representatives of universities, academic institutions, and industrial enterprises expressed their opinion on the problems of training highly qualified personnel in the field of nanomaterials and nanotechnologies, as well as of reducing the time from advancing a scientific idea and its development to the promotion of innovations into the real economy. 
There were two "round-table" meetings:

1. Suggestions and inquiries of innovative projects in the field of nanostructures and nanomaterials.

2. Problems of training the staff in the field of nanomaterials and nanotechnologies.

At the "round-table" meetings, 14 scientists and production workers from different countries (Belarus, Russia, Ukraine) presented their reports.

The reports made at the conference entered into two volumes: "Fullerenes and Nanostructures in Condensed Matter" and "Nanostructures in Condensed Matter," containing over one hundred of peer-reviewed articles written by conference participants.

This special issue of the journal, devoted to the study of fullerenes and nanostructures in condensed matter, is a collection of ten high-quality articles presented at the International Conference FNSCM-2018. Well-known scientists, such as Professors V.A. Borodulya, P.A. Vityaz (Belarus), M.V. Klyuev (Russia), and Zh. Davaasambuu (Mongolia) were among the authors.

We are grateful to the speakers for taking the time to attend the conference and present their overviews. We also acknowledge the help of reviewers for their valuable comments and suggestions and support of the staff of Begell House in publishing this special issue.

Guest editors:

Oleg Glebovich Penyazkov

Academician, Director of the A.V. Luikov Institute

of Heat and Mass Transfer of the National Academy

of Sciences of Belarus

Eduard Mikhailovich Shpilevsky

Professor, leading researcher at the Laboratory

of Synthesis and Analysis of Micro- and Nanoscale

Materials, A.V. Luikov Institute of Heat and Mass Transfer

of the National Academy of Sciences of Belarus 